\section{Should Erythropoiesis-Stimulating Agents Be Used in Predialysis Patients?}

\section{THE "PRO" SIDE}

Anemia results from insufficient production of erythropoietin by the kidneys and is a common complication of chronic kidney disease. It is present in most patients with stage 4 and 5 chronic kidney disease. ${ }^{1}$ Studies have linked untreated anemia in chronic kidney disease to worsening cardiovascular complications, possible acceleration to end-stage renal disease, and death. ${ }^{2}$ Administration of erythropoiesis-stimulating agents has become standard therapy for patients with erythropoietin-deficient anemia who are receiving dialysis. Despite recent concerns regarding the safety of these agents in the predialysis population, ${ }^{3-5}$ these agents should be used for certain carefully selected patients.

A number of studies have examined the use of erythropoiesisstimulating agents in the predialysis period and its impact on outcomes after initiation of dialysis. ${ }^{6-8}$ In one observational study of almost 90000 elderly patients with US Medicare coverage, those who were least consistently treated with erythropoiesisstimulating agents in the 2 years before initiation of dialysis had a higher relative risk of death than those who received the most consistent treatment with these agents (relative risk [RR] 1.46, 95\% confidence interval [CI] 1.245-1.713). ${ }^{6}$ The results of a second study involving a cohort of almost 5000 patients implied a lower risk of death after initiation of dialysis if erythropoiesisstimulating agents were administered before initiation of this therapy (RR 0.81, 95\% CI 0.71-0.91). ${ }^{7}$ Further analysis of retrospective claims data for almost 6000 patients who were receiving hemodialysis indicated that predialysis treatment in the 2 years before the onset of end-stage renal disease significantly lowered the risk of cardiovascular events relative to untreated patients (RR 0.7, 95\% CI 0.61-0.82). ${ }^{8}$ In a systematic review of 15 studies involving a total of 461 predialysis patients with anemia, Cody and others ${ }^{9}$ concluded that treatment with erythropoiesis-stimulating agents corrects anemia, avoids the requirement for blood transfusions, and improves quality of life and exercise capacity. The avoidance of blood transfusions may be of particular importance to patients awaiting kidney transplantation. ${ }^{10}$

Gandra and others, ${ }^{11}$ in their assessment of the effect of treatment with erythropoiesis-stimulating agents on quality of life, reviewed 14 studies performed between 1980 and 2008 that measured energy, fatigue, and/or limitation of physical function/role or activity. The authors concluded that this form of treatment improves hemoglobin concentrations, with associated improvements in self-reported energy and physical function.

Three randomized controlled trials have examined the use of erythropoiesis-stimulating agents in the predialysis popula- tion. ${ }^{3-5}$ The Cardiovascular Risk Reduction by Early Anemia Treatment with Epoetin Beta (CREATE) study ${ }^{3}$ was an open-label randomized trial of 600 patients with chronic kidney disease who were not receiving dialysis and who did not have diabetes mellitus. Patients were randomly assigned to receive epoetin beta for full correction of anemia (target hemoglobin $130-150 \mathrm{~g} / \mathrm{L}$ ) or partial correction of anemia (target hemoglobin $105-115 \mathrm{~g} / \mathrm{L})$. After 3 years of follow-up, there were no differences between the groups in terms of cardiovascular events, but a prespecified secondary analysis showed a higher risk of end-stage renal disease requiring dialysis among the patients with the higher target for hemoglobin concentration.

The Correction of Hemoglobin and Outcomes in Renal Insufficiency (CHOIR) study ${ }^{4}$ was an open-label randomized trial of epoetin alfa given to just over 1400 patients who had chronic kidney disease with or without diabetes. The study compared higher and lower target concentrations of hemoglobin ( 135 versus $113 \mathrm{~g} / \mathrm{L}$ ) in terms of a primary composite end point of death, myocardial infarction, admission to hospital for congestive heart failure, and stroke. The study was terminated early after median 16-month duration of follow up because of an increase in the rate of the composite end point in the higherhemoglobin group (hazard ratio [HR] 1.34, 95\% CI 1.03-1.74). This higher rate was driven by higher rates of death and admission to hospital for congestive heart failure. In addition, there was a strong trend toward a higher rate of end-stage renal disease in the higher-hemoglobin group.

The latest trial, the Trial to Reduce Cardiovascular Events with Aranesp Therapy (TREAT), ${ }^{5}$ was unique in that it was a placebo-controlled trial. In this study, 4000 patients with chronic kidney disease and type 2 diabetes were randomly assigned to treatment with darbepoetin alfa (target hemoglobin $130 \mathrm{~g} / \mathrm{L}$ ) or placebo (with rescue therapy if hemoglobin fell below $90 \mathrm{~g} / \mathrm{L}$ ). Forty-six percent of patients in the placebo arm required rescue therapy with darbepoetin. The median level of hemoglobin achieved was $125 \mathrm{~g} / \mathrm{L}$ in the active treatment arm and $106 \mathrm{~g} / \mathrm{L}$ in the placebo arm. There were no differences between study groups for the composite cardiovascular outcome (cardiovascular events including death, myocardial infarction, myocardial ischemia, congestive heart failure, and stroke) or the renal outcome (death or end-stage renal disease). However, the rate of fatal or nonfatal stroke was higher in the active treatment arm (HR 1.92, 95\% CI 1.38-2.68). Rates of thromboembolism were also higher in the treatment group, and in the subgroup of patients with a history of malignancy, there were higher rates of cancer-related deaths.

Taken together, these studies may indicate to clinicians that the use of erythropoiesis-stimulating agents should be avoided in predialysis patients because of a lack of improvement in cardiovascular and renal outcomes and potential safety concerns. 
However, a number of elements must be taken into consideration before ruling out the use of these agents in this population entirely.

First, hemoglobin itself may be a flawed surrogate marker, since in none of the 3 trials described above was hemoglobin level correlated with the true clinical outcome. ${ }^{12,13}$ Second, in each of these 3 trials, higher doses of erythropoietin-stimulating agents were required in the treatment arms in the attempt to achieve higher hemoglobin targets. In the CREATE trial, the highertarget group received a median dose of $5000 \mathrm{U} /$ week of epoetin beta, whereas the lower-target group received 2000 U/week. In the CHOIR study, the higher-hemoglobin group received a median epoetin alfa dose of $10952 \mathrm{U} /$ week, and the lowertarget group received 5506 U/week. Finally, patients in TREAT who were assigned to receive active treatment with darbepoetin received a median dose of $176 \mu \mathrm{g} /$ month, whereas those in the placebo arm received a median dose of $0 \mu \mathrm{g} /$ month. The hemoglobin levels achieved in the 3 trials were noticeably lower than what was targeted, despite more aggressive dosing of erythropoiesis-stimulating agents. These results may suggest that use of erythropoiesis-stimulating agents at higher dosages, rather than the higher hemoglobin targets, conferred an increased risk of adverse effects. In fact, in a secondary analysis of the CHOIR study, high-dose epoetin was associated with a $57 \%$ increased risk of the primary end point. ${ }^{14}$

The use of erythropoiesis-stimulating agents should not be abandoned in the predialysis population. At the same time, liberal use of these drugs should not be continued for all patients with chronic kidney disease who have anemia. Current guidelines recommend the initiation of erythropoiesis-stimulating agents when hemoglobin falls below $100 \mathrm{~g} / \mathrm{L}$, with a target range for treatment of $100-120 \mathrm{~g} / \mathrm{L} .{ }^{15,16}$ The above evidence is an indication that one size does not fit all members of this particular patient group, and the benefits and risks for individual patients should be given more consideration. For example, patients with diabetes and a prior history of stroke or cancer may well form a subgroup for whom the risk of treatment with erythropoiesis-stimulating agents outweighs the benefits. If these agents are to be used before initiation of dialysis to relieve the symptoms of anemia, avoid the need for transfusion, and improve physical functioning and quality of life, it is imperative to undertake careful monitoring of hemoglobin, as well as the dosage of erythropoiesis-stimulating agent, to limit the risk of adverse outcomes.

\section{References}

1. McClellan W, Aronoff SL, Bolton WK, Hood S, Lorber DL, Tang KL, et al. The prevalence of anemia in patients with chronic kidney disease. Curr Med Res Opin 2004;20(9):1501-1510.

2. Bradbury BD, Fissell RB, Albert JM, Anthony MS, Critchlow CW, Pisoni RL, et al. Predictors of early mortality among incident US hemodialysis patients in the dialysis outcomes and practice patterns study (DOPPS). Clin J Am Soc Nephrol 2007;2(1):89-99.

3. Drüeke TB, Locatelli F, Clyne N, Eckhardt KU, Macdougall IC, Tsakiris $\mathrm{D}$, et al.; CREATE Investigators. Normalization of hemoglobin level in patients with chronic kidney disease and anemia. $N$ Engl $J$ Med 2006;355(20):2071-2084.

4. Singh AK, Szczech L, Tang KL, Barnhart H, Sapp S, Wolfson M, et al.; CHOIR Investigators. Correction of anemia with epoetin alfa in chronic kidney disease. N Engl J Med 2006;355(20):2085-2098.
5. Pfeffer MA, Burdmann EA, Chen CY, Cooper ME, de Zeeuw D, Eckardt FU, et al.; TREAT Investigators. A trial of darbepoetin alfa in type 2 diabetes and chronic kidney disease. $N$ Engl J Med 2009;361(21): 2019-2032.

6. Xue JL, St Peter WL, Ebben JP, Everson SE, Collins AJ. Anemia treatment in the pre-ESRD period and associated mortality in elderly patients. Am J Kidney Dis 2002;40(6):1153-1161.

7. Fink J, Blahut S, Reddy M, Light P. Use of erythropoietin before the initiation of dialysis and its impact on mortality. Am J Kidney Dis 2001;37(2):348-355.

8. Wish JB, Nassar GM, Schulman K, del Aguila M, Provenzano R. Postdialysis outcomes associated with consistent anemia treatment in predialysis patients with chronic kidney disease. Clin Nephrol 2008;69(4):251-259.

9. Cody J, Daly C, Campbell M, Donaldson C, Grant A, Khan I, et al. Recombinant human erythropoietin for chronic renal failure anaemia in pre-dialysis patients. Cochrane Database Syst Rev 2001;(4):CD003266.

10. Locatelli F, Aljama P, Canaud B, Covic A, De Francisco A, Macdougall IC, et al.; Anaemia Working Group of European Renal Best Practice (ERBP). Target haemoglobin to aim for with erythropoiesis-stimulating agents: a position statement by ERBP following publication of the Trial to Reduce Cardiovascular Events with Aranesp Therapy (TREAT) study. Nephrol Dial Transplant 2010;25(9):2846-2850.

11. Gandra SR, Finkelstein FO, Bennett AV, Lewis EF, Brazg T, Martin ML. Impact of erythropoiesis-stimulating agents on energy and physical function in nondialysis CKD patients with anemia: a systematic review. $A m J$ Kidney Dis 2010;55(3):519-534.

12. Singh AK. Diabetes, anemia and CKD: Why TREAT? Curr Diab Rep 2010;10(4):291-296.

13. Cotter DJ, Stefanik K, Zhang Y, Thamer M, Scharfstein D, Kaufman J. Hematocrit was not validated as a surrogate end point for survival among epoetin-treated hemodialysis patients. J Clin Epidemiol 2004;57(10): 1086-1095.

14. Szczech LA, Barnhart HX, Inrig JK, Reddan DN, Sapp S, Califf RM, et al. Secondary analysis of the CHOIR trial epoetin-alpha dose and achieved hemoglobin outcomes. Kidney Int 2008;74(6):791-798.

15. Moist LM, Foley RN, Barrett BJ, Madore F, White CT, Klarenbach SW, et al.; Canadian Society of Nephrology. Clinical practice guidelines for evidence-based use of erythropoietic-stimulating agents. Kidney Int Suppl 2008;(110):S12-8.

16. KDOQI clinical practice guideline and clinical practice recommendations for anemia in chronic kidney disease: 2007 update of hemoglobin target. Am J Kidney Dis 2007;50(3):471-530.

Rene Breault, BScPharm, PharmD

Faculty of Pharmacy and Pharmaceutical Sciences

University of Alberta

Edmonton, Alberta

\section{THE "CON" SIDE}

This debate will be important to hospital pharmacists because anemia is the second most common presentation of disease worldwide. ${ }^{1,2}$ Its most common cause is iron deficiency due to inadequate intake of iron. ${ }^{1,2}$ Secondary contributors to anemia are blood loss, nutritional deficiencies, and myelodysplastic disorders. Anemia due to a lack of erythropoietin accounts for a small proportion of patients and is typically limited to patients with renal failure. As a starting point for this side of the debate, it does not seem to make pharmacological sense to administer an erythropoiesis-stimulating agent to individuals who are already erythropoietin replete. In these patients, a high dose of such an agent may be needed to elicit any additional response over intrinsic production, and this exposure may pose 
additional risk. It makes sense, then, that patients not undergoing dialysis who benefit the most from exogenous administration of erythropoiesis-stimulating agents are those with estimated glomerular filtration rate (eGFR) between 20 and $60 \mathrm{~mL} / \mathrm{min}$ in whom the hormone may be diminished. As I will demonstrate, the enthusiasm to give erythropoiesis-stimulating agents to nondialysis patients has certainly diminished in recent years, to the point that a clinician would be hard pressed to find justification for this type of therapy.

In observational trials involving patients with cancer or chronic kidney disease before and since pharmaceutical erythropoiesis-stimulating agents became available, patients with higher hemoglobin levels have tended to have better outcomes. For example, 10-year mortality was higher for patients with anemia than for those without anemia for every GFR breakpoint, particularly below GFR of $75 \mathrm{~mL} / \mathrm{min}^{3}{ }^{3}$ The strong associations between low hemoglobin level and adverse outcomes led to the belief that increasing hemoglobin would improve outcomes. In the era of erythropoiesis-stimulating agents, many trials have been conducted in a variety of populations to determine whether this assumption is true. What has become clearer through these trials is an appreciation that the regulation of hemoglobin is more complicated than originally envisioned and that other factors are also at play. It was incorrectly thought, for instance, that if hemoglobin was raised, the cardiac deterioration observed in patients with renal failure could be halted or reversed and hence that survival would improve. ${ }^{4.6}$

Hemoglobin trials using erythropoiesis-stimulating agents have had methodological problems. The treatments are difficult to blind, the trials are typically not placebo-controlled, and it may be difficult to control for other factors that influence hemoglobin. The outcomes measured have typically varied as well. From the best of these trials, it appears that prescribing ever-increasing doses of erythropoiesis-stimulating agents may not lead to improved outcomes and may in fact do harm to patients who are already sick. Conversely, patients who are generally well do not seem to need high doses of these agents to achieve target hemoglobin levels. In fact, the only benefit of using erythropoiesis-stimulating agents that has been consistently seen in well-designed trials is a decrease in the rate of blood transfusion. ${ }^{47,8}$

Three major trials have dominated the landscape of use of erythropoiesis-stimulating agents in nondialysis patients. The Correction of Hemoglobin and Outcomes in Renal Insufficiency (CHOIR) study, ${ }^{5}$ the Cardiovascular Risk Reduction by Early Anemia Treatment with Epoetin Beta (CREATE) study, ${ }^{6}$ and the Trial to Reduce Cardiovascular Events with Aranesp Therapy $(\text { TREAT })^{4}$ have provided helpful findings to guide the use of these agents in nondialysis patients. In the CHOIR study, ${ }^{5}$ an open-label study, the investigators found that patients treated to a higher hemoglobin target more often reached the composite end point of death, myocardial infarction, congestive heart failure, admission to hospital or stroke (hazard ratio [HR] 1.34, $p=0.03$ ). Quality of life improved in both groups but did not differ statistically. ${ }^{5}$ In the CREATE study, ${ }^{6}$ another open-label trial, achieving a higher hemoglobin target did not result in a higher rate of first cardiovascular event or changes in left ventricular mass, but did increase the likelihood of subsequent dialysis.
There was improved quality of life in the higher-hemoglobin arm, but given the open-label design, this may have been an artifact. $^{6}$ TREAT, the largest study to date of erythropoiesisstimulating agents in nondialysis patients, and the only one to use a placebo control, ${ }^{4}$ demonstrated no benefit of the drug beyond a 10\% reduction in transfusions, yet did find harm in the form of a doubling of the risk of stroke. This finding alone should give us serious pause. TREAT also had increased rates of thromboembolism and deep venous thrombosis in the active treatment arm, as well as an increase in cancer-related deaths and deaths among those with malignancy at baseline. ${ }^{4}$

Together, these 3 trials tell us that there is either no benefit or increased risk of mortality or cardiovascular complications with erythropoiesis-stimulating agents administered with the goal of achieving higher hemoglobin levels. Point estimates of harm were 34\% (the CHOIR study), ${ }^{5} 22 \%$ (the CREATE study), ${ }^{6}$ and $5 \%$ (TREAT). ${ }^{4}$ Therefore, in addition to the fact that higher doses of erythropoiesis-stimulating agent are not associated with benefit and are perhaps associated with increased risk, it appears that use of any erythropoiesis-stimulating agent (as in TREAT) does not improve hard outcomes. The results of these 3 trials are complementary. The size (4038 participants) and quality of TREAT are impressive, especially in light of this study's demonstration of no benefit of erythropoiesis-stimulating agents in terms of mortality and cardiovascular or renal outcomes, in conjunction with higher risks of stroke, thromboembolism, and possibly cancer. Notably, these results were obtained in patients who had diabetes mellitus and GFR of $20-60 \mathrm{~mL} / \mathrm{min}$, the very population of patients not receiving dialysis who should derive the greatest benefit, given their relative lack of endogenous erythropoietin.

Beyond this trial, there have been a number of reports that erythropoiesis-stimulating agents may stimulate tumour growth and reduce survival in patients with head, neck, breast, uterine, and cervical cancer, as well as various lymphoproliferative malignancies, mixed nonmyeloid cancers, and lung tumours. ${ }^{9-14}$ That there may be tumours sensitive to these agents, at least in these areas, should give clinicians a second serious pause, both for patients already known to have such tumours and for those who may have undiagnosed tumours. The US Food and Drug Administration has stated that the use of erythropoiesis-stimulating agents is "not indicated for patients receiving myelosuppressive chemotherapy when the anticipated outcome is cure". ${ }^{15}$ Use of these agents in patients who are receiving palliative care (to avoid transfusions) must be weighed against the risk of stroke and reduced life expectancy.

It might be argued that patients awaiting a pre-emptive transplant may require an erythropoiesis-stimulating agent to meet the transplant criteria. This narrow exception may well have long-term benefit, provided the criteria are valid. This group of patients fits into the larger group of patients needing "renal replacement therapy", which includes patients who are receiving dialysis.

Efforts to improve hemoglobin concentration should be directed away from erythropoiesis-stimulating agents in favour of optimizing iron therapy and resolving the underlying causes of the anemia (e.g., bleeding, inflammation). For symptomatic patients with low hemoglobin $(<90 \mathrm{~g} / \mathrm{L})$, the decision to use a 
rescue dose of an erythropoiesis-stimulating agent, as was done in TREAT, may be reasonable, but it should be done with due caution and with lower treatment targets. The decision to use an erythropoiesis-stimulating agent ultimately rests with the patient, after the clinician has provided the sum of the data to date. As for me, sitting on either side of the clinician's desk, I cannot justify the use of erythropoiesis-stimulating agents in patients who are not receiving dialysis - the risk is too great, the benefit too small.

\section{References}

1. DeMeayer EM, Adiels-Tegman M. The prevalence of anaemia in the world. World Health Stat Q 1985;38(3):302-316.

2. De Benoist B, McLean E, Egli I, Cogswell M, editors. Worldwide prevalence of anaemia 1993-2005: WHO global database on anaemia. Geneva (Switzerland): World Health Organization; 2008 [cited 2010 Oct 11]. Available from: http://whqlibdoc.who.int/publications/2008/9789241596657_ eng.pdf

3. Astor BC, Coresh J, Heiss G, Pettitt D, Sarnak MJ. Kidney function and anemia as risk factors for coronary heart disease and mortality: the Atherosclerosis Risk in Communities (ARIC) Study. Am Heart J 2006; 151(2):492-500.

4. Pfeffer MA, Burdmann EA, Chen CY, Cooper ME, de Zeeuw D, Eckardt FU, et al.; TREAT Investigators. A trial of darbepoetin alfa in type 2 diabetes and chronic kidney disease. N Engl J Med 2009;361(21):2019-2032.

5. Singh AK, Szczech L, Tang KL, Barnhardt H, Sapp S, Wolfson M, et al.; $\mathrm{CHOIR}$ Investigators. Correction of anemia with epoetin alfa in chronic kidney disease. N Engl J Med 2006;355(20):2085-2098.

6. Drüeke TB, Locatelli F, Clyne N, Eckhardt KU, Macdougall IC, Tsakiris $D$, et al.; CREATE Investigators. Normalization of hemoglobin level in patients with chronic kidney disease and anemia. N Engl J Med 2006;355(20):2071-2084

7. Rizzo JD, Brouwers M, Hurley P, Seidenfeld J, Arcasoy MO, Spivak JL, et al.; American Society of Hematology and American Society of Clinical Oncology Practice Guideline Update Committee. American Society of Hematology/American Society of Clinical Oncology clinical practice guideline update on the use of epoetin and darbepoetin in adult patients with cancer. Blood 2010;116(20):4045-4059.

8. Seidenfeld J, Piper M, Bohlius J, et al. Comparative effectiveness of epoetin and darbepoetin for managing anemia in patients undergoing cancer treatment. Comparative Effectiveness Review No. 3. AHRQ Publ. 06EHC008-1. Rcokville (MD): Agency for Healthcare Research and Quality;
2006 [cited 2010 Oct 11]. Available from: http:// effectivehealthcare. ahrq.gov/index.cfm/search-for-guides-reviews-and-reports/?pageaction= displayproduct\&productid $=35$

9. Henke M, Laszig R, Rübe C, Schäfer U, Haase KD, Schilcher B, et al. Erythropoietin to treat head and neck cancer patients with anaemia undergoing radiotherapy: randomised, double-blind, placebo-controlled trial. Lancet 2003;362(9392):1255-1260.

10. Leyland-Jones B, Semiglazov V, Pawlicki M, Pienkowski T, Tjulandin S, Manikhas G, et al. Maintaining normal hemoglobin levels with epoetin alfa in mainly nonanemic patients with metastatic breast cancer receiving firstline chemotherapy: a survival study. J Clin Oncol 2005;23(25):5960-5972.

11. Overgaard J, Hoff C, San Hansen H. Randomized study of the importance of novel erythropoiesis stimulating protein (Aranesp) for the effect of radiotherapy in patients with primary squamous cell carcinoma of the head and neck (HNSCC): The Danish Head and Neck Cancer Group DAHANCA 10 [abstract]. Eur J Cancer 2007;7 Suppl 5:Abstract 6LB.

12. Wright JR, Ung YC, Julian JA, Pritchard KI, Whelan TJ, Smith C, et al. Randomized, double-blind, placebo-controlled trial of erythropoietin in non-small-cell lung cancer with disease-related anemia. J Clin Oncol 2007;25(9):1027-1032.

13. Overgaard J. Interim analysis of DAHANCA 10: Study of the importance of novel erythropoiesis stimulating protein (Aranesp $\left.{ }^{\circledR}\right)$ for the effect of radiotherapy in patients with primary squamous cell carcinoma of the head and neck. Aarhus (Denmark): Danish Head and Neck Cancer Group; 2006 [cited 2010 Oct 11]. Available from: www.dahanca.dk/ get_media_file.php?mediaid $=125$

14. Smith RE Jr, Aapro MS, Ludwig H, Pintér T, Smakal M, Ciuleanu TE, et al. Darbepoetin alpha for the treatment of anemia in patients with active cancer not receiving chemotherapy or radiotherapy: results of a phase III, multicenter, randomized, double-blind, placebo-controlled study. J Clin Oncol 2008;26(7):1040-1050.

15. FDA approves a risk evaluation and mitigation strategy (REMS) to ensure the safe use of erythropoiesis-stimulating agents (ESAs). Silver Spring (MD): US Food and Drug Administration; 2010 [cited 2011 Mar 23]. Available from: www.fda.gov/AboutFDA/CentersOffices/CDER/ ucm 200847.htm

\section{Dan Martinusen, PharmD}

Pharmacy

Royal Jubilee Hospital

Victoria, British Columbia

\begin{tabular}{lll}
\multicolumn{2}{c}{ Advertisers } & \\
\hline & Ad Page & Prescribing Information \\
\hline Amgen / Neulasta & 100 & $158-160$ \\
\hline CATIE / HIV Drug Treatment Guide & 99 & - \\
\hline Hospira / Docefaxel & 96 & - \\
\hline Pharmaceutical Partners of Canada / Corporate & IFC & - \\
\hline Pharmaceutical Partners of Canada / Corporate & OBC & - \\
\hline Sandoz / Piperacillin-Tazobactam & 94 & -
\end{tabular}

